\section{Stimulus induced attenuation of rat vocalizations to tail shock: Shock intensity effects*}

\author{
PIETRO BADIA AND STUART CULBERTSON \\ Bowling Green State University, Bowling Green, Ohio 43402
}

Three studies are reported dealing with inhibition of distress vocalizations to shock by a preceding stimulus. Two factors were considered: shock intensity and postural adjustments. Shock intensity was varied in $2 . \mathrm{V}$ steps from 8 to $18 \mathrm{~V}$ in Study A, 12 to $22 \mathrm{~V}$ in Study B, and 18 to $28 \mathrm{~V}$ in Study C. Postural changes were controlled by using a restraining cage and applying shock to the tail. Stimulus-induced suppression was relatively constant at intermediate intensities but at the highest intensities it did not occur. Number and duration of vocalizations increased with intensity. Postural adjustment was not a factor.

It has been found that significantly fewer distress vocalizations occur to shock preceded by a stimulus than to shock occurring alone (Badia, Defran, \& Lewis, 1968). This phenomenon of stimulus-induced suppression is extremely reliable across experiments and is demonstrated by nearly all Ss. Since inhibition or attenuation of vocalization occurs on the first trial and remains constant within and between experimental sessions, it has been speculated that nonassociative factors such as sensory interaction or specific intermodel connections are responsible.

Other findings of stimulus-induced inhibition of vocalization to shock can be briefly summarized: (1) Fewer vocalizations occur when either a visual or auditory stimulus precedes shock but not when a stimulus in the same modality as shock is used; (2) attenuation of vocalizations occurs when the stimulus preceding shock is an energy increase (onset) but not an energy decrease (offset); (3) relatively long and short interstimulus intervals-.5, 1,3 , and 6 sec-result in attenuation, but simultaneity of stimulus and shock does not;

* This research was supported in part by USPHS Grant MH-16307-01.
(4) delayed and trace procedures result in similar attenuation; (5) vocalization growth curves to shock emerge at a similar rate for shock-alone and shock preceded by a stimulus.

Since previous studies have used shock intensities only slightly greater than the vocalization threshold, the relationship between stimulus-induced inhibition and shock intensity is not known. In addition, postural adjustments related to contact on the grid bars were not controlled in earlier studies. It is possible that these adjustments, rather than sensory phenomena per se, were responsible for stimulus-induced inhibition of vocalizations.

The present study investigated stimulus-induced inhibition of vocalization to different intensities of shock. In addition, the effects of postural responses on the reception of shock directly to the rat's tail.

\section{SUBJECTS}

Naive albino rats (Holtzman) between 90 and 120 days old were used. Ss were housed individually and maintained on ad lib food and water. Ten male Ss were used in Study A. In Study B five females were run, and four of these were continued in Study C. shock were eliminated by applying
APPARATUS

The experiments were conducted in a clear Plexiglas restraining compartment similar to that described by Azrin, Hopwood, \& Powell (1967). Inside dimensions of this box were: $5^{3 / 4}$ in. wide on the front (stimulus) panel and 2 in. wide at the rear of the box, $71 / 4$ in. long, and $73 / 4$ in. high. Ss were further restrained by placing the tail through the rear of the box and taping it to a 6-in. insulated rod extending from the back wall of the chamber and forcing the animal to face the front wall. The restraint box was then placed in a ventilated acoustical chamber with an ambient noise level of $42 \mathrm{~dB}$, as measured on the $C$ scale of a General Radio sound-level meter. Shock was delivered to the Ss' tails for $2 \mathrm{sec}$ through a brass electrode consisting of two rods separated 1-2/5 in. apart by a Plexiglas insulator. Current flowing between these two rods was generated by a Grass Model SD 5 stimulator set at five pulses per second, with a 20-msec duration per pulse. The 3-sec preshock signal consisted of a jeweled (24-V, $509 \mathrm{~K}$ ) bulb 1-in. in diam, the center of which was mounted $1 \frac{1 / 2}{\text { in }}$, to the right of center of the restraining box and 6 in. from the floor. Vocalizations were picked up by an Ampex (Model 2001) microphone placed $1 \frac{1}{2}$ in. from the left center of the experimental chamber and 6 in. above the floor. The vocalizations were then amplified by an Ampex 1000 tape recorder. To eliminate low-frequency noises below $1,500 \mathrm{~Hz}$ caused by S's movement, the signal was filtered through an HPM-1500 UTC filter. After filtering, the signal was fed into a BRS emitter follower and then to a Schmitt trigger. The output from this trigger was then displayed as discrete responses on Sodeco counters. For vocalization duration, signals were taken from the tape recorder, and the total duration of the 2-sec shock period that $S$ spent vocalizing was displayed on a Hunter Klockcounter.
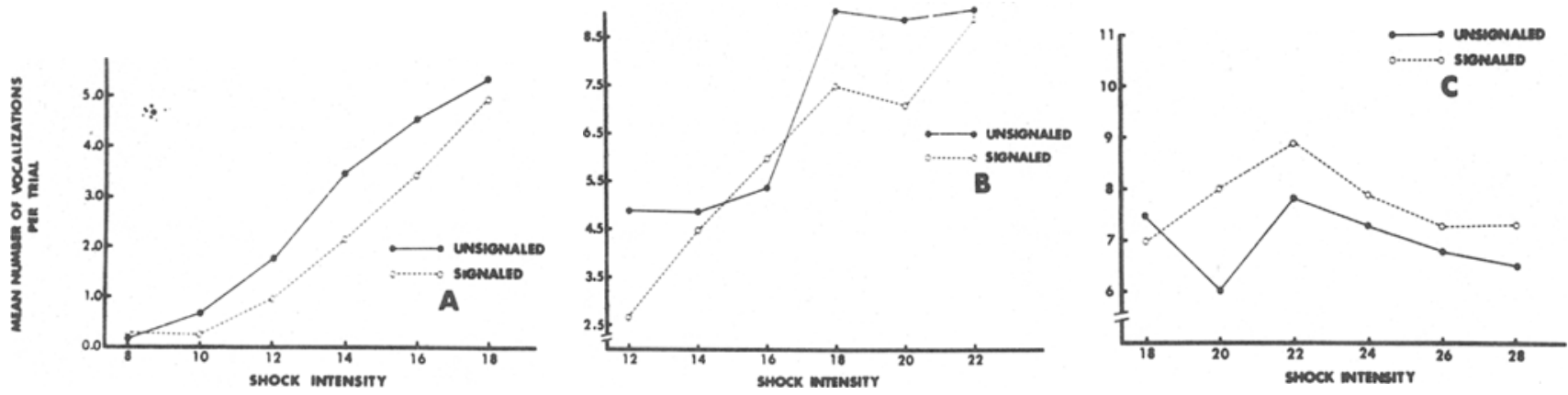

Fig. 1. Mean number of vocalizations to shock alone vs shock preceded by a stimulus as a function of shock intensity for all three studies. 

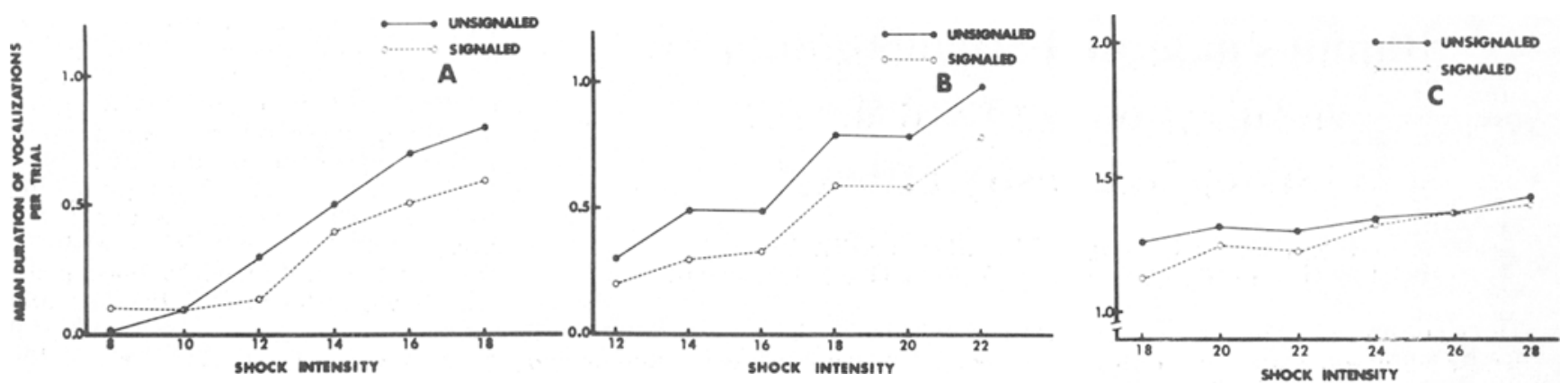

Fig. 2. Mean duration of vocalizations to shock alone vs shock preceded by a stimulus as a function of shock intensity for all three studies.

\section{PROCEDURE}

A within-Ss design was used in that all Ss in each experiment received ejght trials at each of six shock intensities. Half of the eight trials at a given intensity were signaled and half were unsignaled. Thus each $S$ received a total of 48 trials randomized with respect to both intensity and signal or no-signal. A trial consisted of a 60 -sec intertrial interval followed by a $3-\mathrm{sec}$ light on a stimulus trial or no light on a no-stimulus trial. The stimulus overlapped the shock which was on for 2 sec. In Study A shock was varied in 2 -sec steps from 8 to $18 \mathrm{~V}$, while shock was varied from 12 to $22 \mathrm{~V}$ in Study B, and in Study C the intensity ran from 18 to $28 \mathrm{~V}$.

\section{RESULTS AND DISCUSSION}

Two measures of vocalization were recorded for each study: (1) frequency of discrete vocalizations on each trial (2) duration of time spent vocalizing.

As noted previously, shock was varied in $2-\mathrm{V}$ steps from 8 through $18 \mathrm{~V}$ in Study A, 12 through $22 \mathrm{~V}$ in Study B, and 18 through $28 \mathrm{~V}$ in Study C. The frequency of discrete vocalizations to each intensity for shock preceded by a stimulus and for shock alone can be seen in Fig. 1. It is clear that the frequency of vocalizations from 8 through $18 \mathrm{~V}$ significantly increased as a function of shock intensity $(F=21.7, \mathrm{df}=5 / 45$, $p<.001$ ) and that stimulus-induced suppression consistently occurred from 10 through $18 \mathrm{~V} \quad(\mathbf{F}=9.8$, $\mathrm{df}=1 / 9, \mathrm{p}<.05)$. The interaction between these two conditions was not significant. Studies B and C show that as $\mathrm{Ss}$ are exposed to higher intensities vocalization asymptotes at approximately eight per trial. However, stimulus-induced suppression tends to break down and actually reverse at the highest shock levels. This latter finding was not significant ( $p>.25$ ). Observations of the Ss suggested that they tended to emit fewer but longer vocalizations at higher shock intensities. Therefore, a more appropriate measure would appear to be a duration rather than a frequency measure. Figure 2 shows duration of vocalization to different intensities with and without a preceding stimulus before the 2 -sec shock. The data are very orderly and they show that vocalization duration increases with increases in intensity to an asymptote of approximately $20 \mathrm{~V}$. Analysis of variance indicated that for Study A the duration measure significantly increased across intensity $(\mathrm{F}=22.5, \mathrm{df}=5 / 45, \mathrm{p}<.001)$ and that significant stimulus-induced suppression also occurred ( $F=14.7$, $\mathrm{df}=1 / 9, p<.01$ ). Both of these latter findings were also found to be significant for Study B but not for Study C.

Two main conclusions are supported by the data. Since restraint was used and shock was applied directly to the tail, it would appear that this procedure clearly rules out the possibility that animals made postural adjustments to reduce shock intensity. Therefore, it would appear reasonable to conclude that inhibition of vocalization is not a function of postural adjustments. Secondly, it is obvious that stimulus-induced suppression of vocalization does not occur at high shock intensities. Whether the mechanism is sensory interaction, specific intermodal connections, or something else, it apparently does not operate at high shock intensities. However, it is also apparent that within a relatively broad band of shock intensities, stimulus-induced inhibition is relatively constant.

\section{REFERENCES}

AZRIN, N. H., HOPWOOD, J., \& POWELL, J. A rat chamber and electrode procedure for avoidance conditioning. Joumal of the Experimental Analysis of Behavior. 1967, 10, 291-298.

BADIA, P., CULBERTSON, S., DEFRAN, R $H$ \& LEWIS, $P$. Attenuation of rat vocalization to shock by a stimulus: Sensory interaction effects? Journal of Comparative \& Physiological Psychology. in press.

BADIA P. DEFRAN, R. H., \& LEWIS, P. CS-US interval and suppression of unconditioned vocalization to shock: Associative or non-associative. Psychonomic Science, 1968, 13, 269-270. 